\title{
Detection and Characterization of BCR-ABL Transcripts in Bangladeshi CML Patients by Cost Effective RT-PCR
}

\author{
Md. Shahjalal Soad, Khadiza Akhter, Hossain Uddin Shekhar* \\ Department of Biochemistry and Molecular Biology, University of Dhaka, Dhaka, BANGLADESH \\ ${ }^{*}$ Corresponding Contact: \\ Email: hossainshekhar@du.ac.bd
}

\begin{abstract}
Philadelphia (Ph) chromosome or the BCR-ABL fusion gene is used to diagnose, determine treatment strategy of chronic myelogenic leukemia (CML) and acute lymphoblastic leukemia (ALL). The fusion gene transcript may vary depending on the reciprocal translocation between chromosome 9 and 22 . Hence, identification and characterization of the BCR-ABL transcripts are important for the treatment and management of leukemia patients. In this study, a primer set and clinical molecular diagnosis assay were established to identify the BCR-ABL transcripts by conventional polymerase chain reaction (PCR). A parallel analysis was done for quantitative real-time polymerase chain reaction (Q-PCR) and conventional PCR. This study is based on reverse transcriptase PCR (RT-PCR) of 87 CML patients' RNA to generate total cDNAs and the selection of the BCRABL transcripts by conventional polymerase chain reaction using specific primer set. A BCR primer BCR-e12: GCAGAGTGGAGGGAGAACAT and a reverse ABL primer ABL-a3: GCTTCACACCATTCCCCATT was established to select three different Philadelphia major transcripts (b3a2, b2a2 and b3a3). Sixty-one Philadelphia positive samples ( $35 \mathrm{~b} 3 \mathrm{a} 2,22 \mathrm{~b} 2 \mathrm{a} 2$ and $4 \mathrm{~b} 3 \mathrm{a} 3$ fragments) were detected out of $87 \mathrm{CML}$ patients. Q-RT-PCR was then performed, and ten discrepancies were found in the study. Four samples found positive in conventional PCR resulted negative in Q-PCR and other six samples (positive in $\mathrm{Q}-\mathrm{PCR}$ ) gave the negative result in conventional PCR. Though Q-PCR is quantitative and highly specific, it is expensive and can't characterize BCR-ABL fragments. On the other hand, conventional PCR is less reliable but is inexpensive and helpful for characterization of the target fusion gene. Performing both Q-PCR and conventional PCR can detect each and every positive case of CML as well as give no false positive or false negative result.
\end{abstract}

Keywords: Chronic myelogenous leukemia, Philadelphia chromosome, Realtime PCR, Conventional PCR 


\section{INTRODUCTION}

Chronic myelogenous (or myeloid or myelocytic) leukemia (CML) is a kind of leukemia characterized by the increased and uncontrolled growth of white blood cells. Initially, it is responsible for the unregulated growth of myeloid cells in the bone marrow, and then these cells accumulate in the blood. There are three possible phases of CML: chronic, accelerated and blast phases (Sawyers 1999).

In chronic phase, the CML develops very slowly. People, in this phase, usually have no symptoms or only minor symptoms. In the chronic phase, there are $5 \%$ or fewer blast cells in the blood and bone marrow. In a small number of people, the leukemia may gradually move into an accelerated phase. In this phase, there are $6-30 \%$ blast cells in the blood and bone marrow. In the blast crisis phase, cells remain immature and resemble myeloblasts found in acute leukemias. The abnormal white blood cells and blast cells do not protect against infection. Other complications include bruising, bleeding from the gums. Philadelphia chromosome $(\mathrm{Ph})$ is the main causative agent for chronic myelogenic leukemia (CML). Philadelphia chromosome arises as a translocation (Rowley 1973).

The ABL gene which is a protooncogene has a similarity with Abelson murine leukemia viral oncogene homolog 1 is found on chromosome 22, and the BCR gene (Breakpoint cluster region) is mapped to chromosome 9. The joining of $3^{\prime}$ sequences of the tyrosine kinase c-ABL proto-oncogene on chromosome 9 to the $5^{\prime}$ sequences of the BCR gene on chromosome 22 is the result of Ph. The positions, where the breaks occur at, are q34 and $\mathrm{q} 11$ ( $\mathrm{t}(\mathrm{q} ; 22)$ (q34;q11) (Hermans et al. 1987).

This head to tail fusion of BCR and ABL genes encodes a BCR-ABL fusion protein. This fusion protein has increased tyrosine kinase activity (Melo et al., 2003). Constitutive activation of ABL tyrosine kinase promotes cell proliferation (Zhao 1997). The BCR-ABL fusion protein can vary from $190 \mathrm{kDa}$ to $230 \mathrm{kDa}$, depending on the site of the breakpoint in the BCR gene (Chasseriau 2004). In CML, the breakpoints on chromosome 22 are restricted to 'major breakpoint cluster region' (M-BCR) of the BCR gene, leading to transcripts with different types of BCR-ABL junctions, dependent on the position of the breakpoint in BCR after exon 13 or exon 14. These fusion transcripts (e13a2 or b2a2, e14a2 or b3a2) encode a BCR-ABL protein of $210 \mathrm{kDa}$, called p210BCR/ABL.

A second breakpoint cluster region called 'minor breakpoint cluster region' (m-BCR) results in e1a2 junction. This results in the production of a BCR-ABL protein of $190 \mathrm{kDa}$ (p190BCR/ABL) (Suh et al. 2000). The e1a2 type of transcript has been found to be associated with ALL. But in rare cases of CML, expression of only this type of transcript has also been reported (Westbrook et al. 1992).

Finally, a very rare proportion of $\mathrm{Ph}+\mathrm{CML}$ patients presents a larger BCR-ABL fusion transcript that results from a fusion between BCR exon 19 and ABL exon 2. It produces an e19a2 junction and encodes a larger $230 \mathrm{kD}$ fusion protein, p230BCR-ABL (Pane 1996). It has been associated with CML with the maturation of neutrophils (Ohsaka et al. 2002).

Philadelphia chromosome is found in up to $95 \%$ of CML patients. It also occurs in approximately $20-50 \%$ of adult ALL and 5\% of childhood (Priest et al. 1980, Sandberg et al. 1980). But Philadelphia chromosome is rare in acute myeloid leukemia (AML), being detected in approximately 1\% of cases (Madashira 2014).

Bangladesh is a developing country with 160 million peoples, and this population is increasing day by day. This country is facing a serious threat of food adulteration and as a 
result, people are affected by various genetic and nongenetic diseases. In addition to exposure to high level of radiation, smoking, exposure to pesticides are increasing the susceptibility to various forms of cancers. As a result, nowadays the number of CML and ALL patients having Philadelphia chromosome is increasing at an alarming rate. There is neither an established cancer registry nor any high level data preservation facility available in the hospitals of Bangladesh.

In developed countries, improvement in the diagnosis and management of CML and ALL has decreased the mortality of these patients (Tahira et al. 2015). Diagnosis of CML and ALL process are improving in developing countries like Iran, India etc. using molecular technique (Yaghmaie 2008, Anand 2012, Jobanputra 1999). Misclassifications for leukemia can be avoided using the most updated, reliable molecular technique for diagnosis of leukemia. Additionally, the technique must have to be inexpensive because management process of leukemia needs frequent diagnosis to check the remission of the disease after the treatment using chemotherapy, bone marrow transplantation or tyrosine kinase inhibitor etc. A variety of tests are used to diagnose, determine disease phase, and monitor Philadelphia chromosome, including karyotyping (Ding 2015), Southern blot analysis (Hochhaus 1996), fluorescence in situ hybridization (FISH), reverse-transcription polymerase chain reaction (RT-PCR) (Hooberman 1990).

In approximately, 95\% cases cytogenetic analysis can detect the Philadelphia chromosome, and in $5 \%$ cases, Philadelphia chromosome is not visible using karyotyping. However this $5 \%$ BCR- ABL fusion gene can be detected by polymerase chain reaction (PCR) (Neumann F et. al 2003). The most sensitive PCR tests can detect as few as one in 1,000,000 cells.

Characterization the Philadelphia chromosome's transcripts and development of a technique based on the principle of gel electrophoresis and/ or capillary electrophoresis to identify the transcripts in a rapid and precise manner was the aim of the study. The objectives of the study also included establishment of a primer set for the detection of BCR-ABL fusion gene, development of a reliable and cost effective procedure to diagnose Philadelphia chromosome in CML and ALL patients.

\section{Methods AND MATERIALS}

\section{Study subjects and sample collection}

This study was conducted with the blood sample of Chronic Myelogenic Leukemia (CML) patients and normal individuals who came for the diagnosis of Philadelphia Chromosome in Bangabandhu Sheikh Mujib Medical University (BSMMU), Shahbag, Dhaka-1000 from the year 2012 to 2015. Along with demographic data, following information were taken as part of the research: $\mathrm{CBC}$ test result, time of $\mathrm{CBC}$ diagnosis, detailed clinical history and the previous diagnosis result of follow-up patients.

In selection procedure for the patient and control, inclusion criteria included the following: (1) Cytogenetic- or PCR-based diagnosis of any phase of Ph $+\mathrm{CML}$, (2) Written informed consent prior to any study procedures being performed, (3) Patients of any ages were included, (4) Both male and female were included for positive and negative control, (5) Only individuals without Philadelphia fusion genes were studied for control groups.

About four $\mathrm{mL}$ of venous blood was drawn from each individual following all aseptic precautions with the help of a trained person, using a disposable syringe. The drawn blood was then stored at $-20^{\circ} \mathrm{C}$ until further use. Bone marrow sample was obtained through a procedure called a bone marrow aspiration and biopsy, and it was collected by a doctor. 


\section{RNA extraction}

Whole blood and Bone Marrow was collected in tubes with RNA stabilizer (PAXgene ${ }^{\mathrm{TM}}$ (PreAnalytiX). REVERTA-L RT reagents kit was used for complementary DNA (cDNA) synthesis from RNA extracted from biological samples.

\section{Primer Selection}

The sequences of the primers are listed in table 1 . We wanted to have only one sense primer associated with one transcript. We used a primer specific for exon e12 for the detection of all fragments of major BCR. Specific primers for e1 and e19 were chosen for detection of breakpoints respectively in minor BCR and micro BCR regions. The ABL primer was specific for exon a3 and can thus detect junctions in a2 and a3 according to the shortness of the a2 exon.

Table 1: Primer selection for RT-PCR analysis for BCR-ABL P190, P210 and P230 fusion gene

\begin{tabular}{|l|l|}
\hline Primer code & Sequence $\left(5^{\prime}{ }^{\prime} \mathbf{3}^{\prime}\right)$ \\
\hline BCR-e1 & TGGAGGAGGTGGGCATCTAC \\
\hline ABL-a3 & GCTTCACACCATTCCCCATT \\
\hline BCR-e12 & GCAGAGTGGAGGGAGAACAT \\
\hline BCR-e19 & CCTCGCAGAACTCGCAACAG \\
\hline G6PD-F & GATGCCTTCCATCAGTCGGA \\
\hline G6PD-R & GCTCACTCTGTTTGCGGATG \\
\hline
\end{tabular}

\section{Conventional PCR}

The PCR reaction medium consisted of $2 \mu \mathrm{L}$ cDNA, $9 \mu \mathrm{L}$ Master Buffer (Texas Biogene), 0.6 $\mu \mathrm{L}$ G6PD-F, 0.6 $\mu \mathrm{L}$ G6PD-R, 0.75 $\mu \mathrm{L}$ BCR- e12, $0.75 \mu \mathrm{L}$ BCR- e1, $0.75 \mu \mathrm{L}$ BCR- e19, 0.75 $\mu \mathrm{L}$ ABL- a3 and $0.15 \mu \mathrm{L}$ Taq polymerase. The primers were ordered from Active Oligos Company. PCR was performed using ProFlex ${ }^{\mathrm{TM}}$ PCR System. To exclude a false negativity, RT-PCR for G6PD mRNA was performed, in parallel, under the same conditions as for BCR-ABL RT-PCR.

\section{Electrophoresis}

PCR product was then analyzed by agarose gel electrophoresis using Biometrasystem. Agarose gel was produced by mixing $2 \mathrm{~g}$ agarose powder in $100 \mathrm{~mL} 1 \mathrm{X}$ TAE buffer. Ethidium bromide $(0.6 \mu \mathrm{L})$ was mixed with the gel to make the DNA visible under UV light. PCR products in the agarose gel were placed in the Vilber lourmat infinity machine and detected.

In this study QIAxcel Advanced System was used for capillary electrophoresis.

\section{Rea- time PCR}

Real-Time test for detection and quantification of mRNA chimeric gene BCR-ABL (M$\mathrm{BCR})$ and mRNA gene ABL in the clinical material was performed by PCRSacace ${ }^{\mathrm{TM}} \mathrm{BCR}-$ ABL M-BCR Real-TM Quant. 
For each quantitative run:

- 5 standards (QS1, QS2, QS3, QS4, QS5) M-BCR-ABL mix was prepared and 1 Negative Control (DNA-buffer) was also prepared by adding $10 \mu \mathrm{l}$ of these reagents to the appropriate tube.

- 3 standards (QS1, QS2, QS3) and 1 Negative Control (DNA buffer) by adding $10 \mu \mathrm{l}$ of these reagents to the appropriate tube was prepared for N-ABL mix.

For each qualitative run:

- 1 standard (QS5) and 1 Negative Control (DNA-buffer) by adding $10 \mu$ of these reagents to the appropriate tube was prepared for M-BCR-ABL mix

- 1 standard (QS3) and 1 Negative Control (DNA-buffer) by adding $10 \mu$ of these reagents to the appropriate tube was prepared for N-ABL mix.

\section{Data Analysis}

The results were interpreted through the presence of crossing of fluorescence curve with the threshold line and in accordance with instrument's instructions. The cDNA M-BCR-ABL was detected in the tubes with PCR- mix-1 M-BCR-ABL and CDNA of genenormalizer/ internal control (IC) ABL was detected in the tubes with PCR-mix-1 N-ABL.

Screening (qualitative) format

The presence of fluorescent signal curves crossing a threshold line in the tubes with a PCR-mix-

$1 \mathrm{M}$ - BCR-ABL indicated the presence of BCR-ABL mRNA transcript in the sample. So the result was positive. The absence of a positive signal in the PCR-mix-1 M- BCR-ABL with a valid value of the genenormalizer signal with the mix N-ABL indicated a negative result.

\section{Quantitative format}

The following formula was used for the calculation of the normalized concentration of RNA M-BCR-ABL in the clinical and control samples:

Concentration $=$ Number copies cDNA M- BCR-ABL / number copies cDNA N-ABL.

\section{RESULTS}

This study included CML patients as the target population. Eighty-seven patients were subjects of this study. For negative control, we used patient's sample that had no evidence of BCR-ABL gene. Most of the patients who came for diagnosis of BCR-ABL translocation were male (Figure 1).

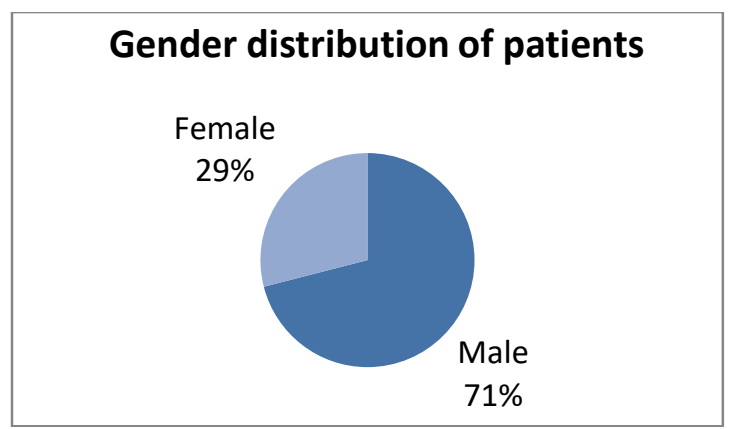

Figure 1: Percentage distribution of CML patients through male and female 
A total of 87 patients' PCR products were analyzed by agarose gel electrophoresis, and it was found that 61 patients were with BCR-ABL translocation and 26 patients without BCR- ABL translocation. An agarose gel picture is given (Figure 2) with 14 patients and one marker.

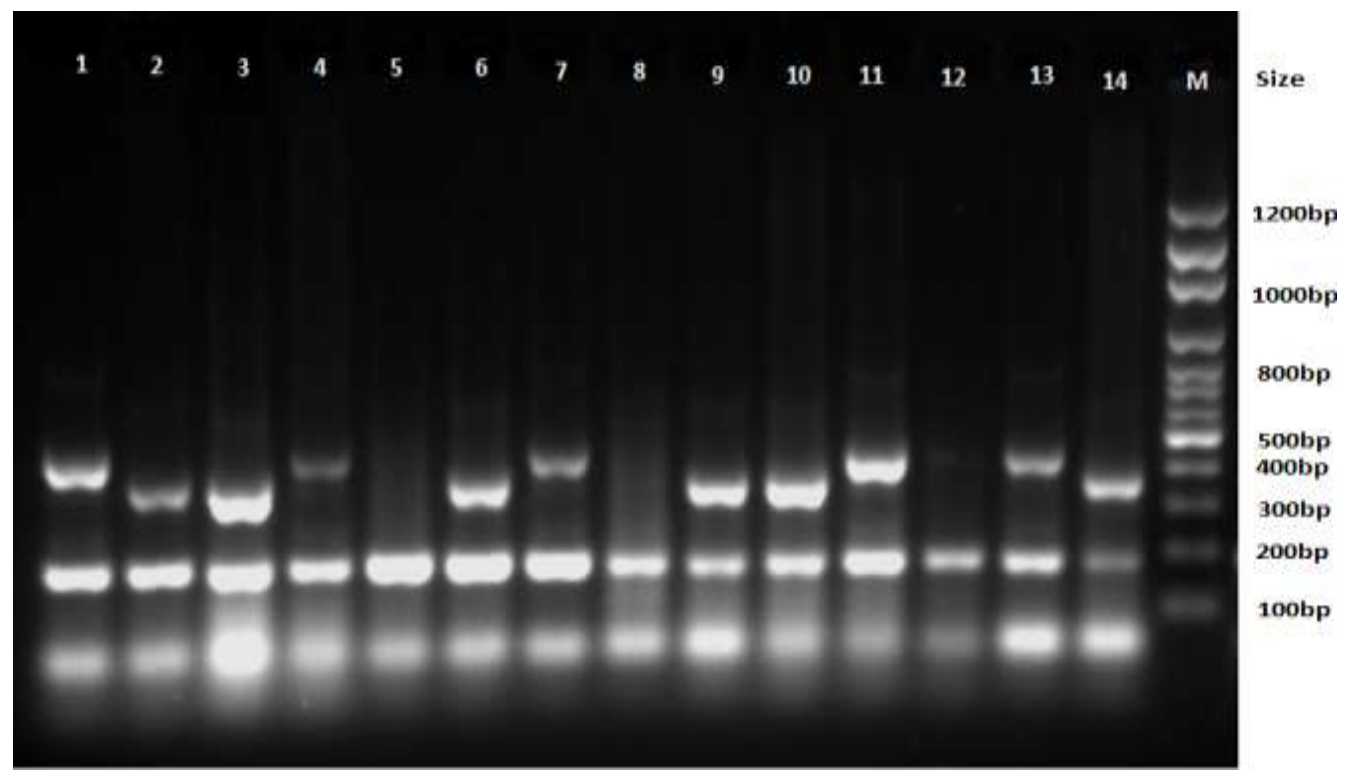

Figure 2: Ethidium bromide-stained agarose gel. 14 patients have been showed in this agarose gel and at the right, a marker has been loaded to compare with the patient's PCR product. The bp of the marker has been presented at the right side of the gel. There are two breakpoints shown in this picture. One is around $440 \mathrm{bp}$ and the other is around 370 bp. Every PCR product shows a band in around $200 \mathrm{bp}$ for glucose 6 phosphate dehydrogenase (G6PD). In this picture column 1, column 4, column7, column 11 and column 13 shows band at $440 \mathrm{bp}$ which is for b3a2. On the other hand column 2, column 3 , column 6, column 9, column 10, column 14 shows band at $370 \mathrm{bp}$ which corresponds to b2a2 major breakpoint. Column 5, column 8 and column 12's PCR product hadn't shown any band for BCR-ABL fusion gene which means they were BCR-ABL negative.

After agarose gel electrophoresis the PCR products remaining were further used for capillary electrophoresis to authenticate the agarose gel electrophoresis result. All of the 87 patients were used for capillary electrophoresis and it was found that the both capillary electrophoresis and agarose gel electrophoresis gave the same result. 


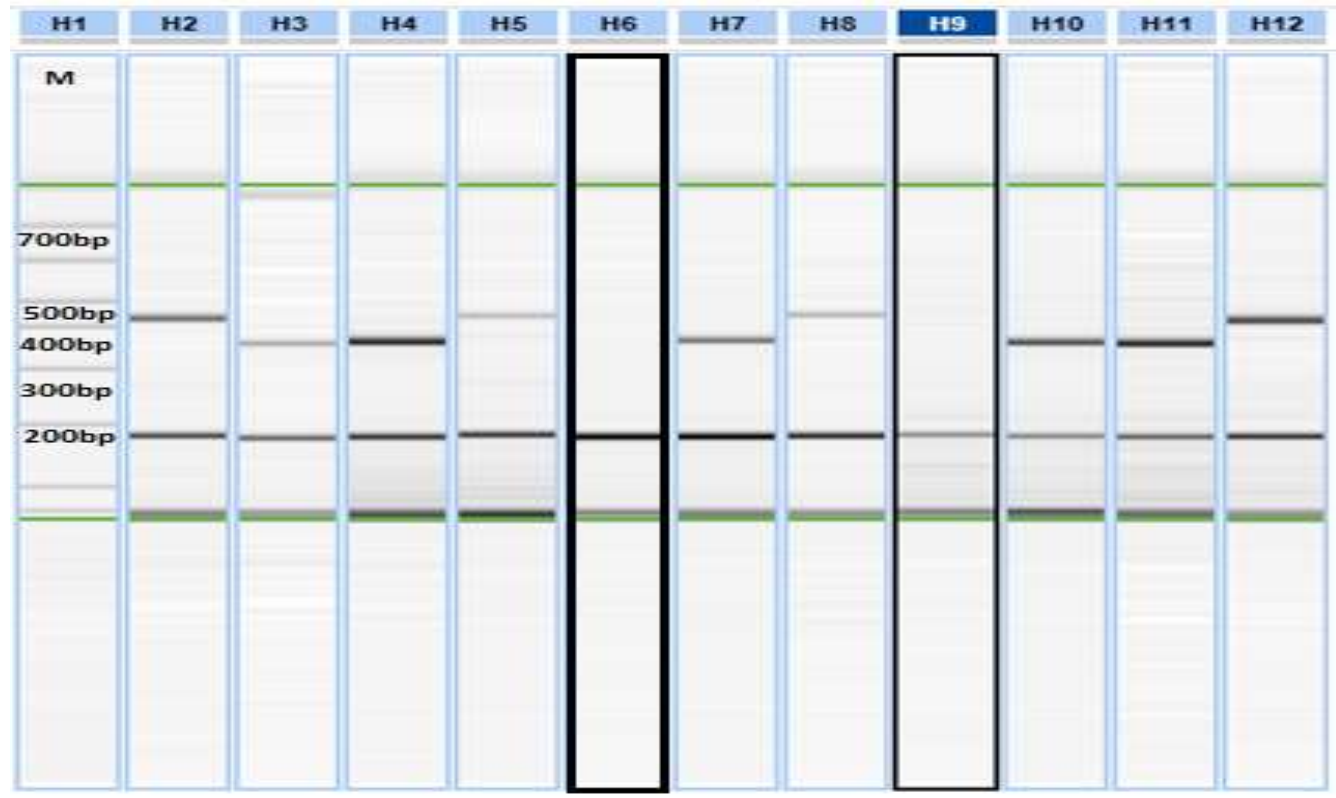

Figure 3: Capillary gel electrophoresis result. H1 column represents the molecular marker and the following columns represent the PCR products of the patients. $\mathrm{H} 2, \mathrm{H} 5, \mathrm{H} 8$ and H12 show BCR-ABL fusion products at $440 \mathrm{bp}$. H3, H4, H7, H10 and H11 PCR products show BCR-ABL fusion products at $370 \mathrm{bp}$. No band was found for $\mathrm{H} 6$ and $\mathrm{H} 9$.

In this study 61 samples gave Philadelphia major translocation among which 35 patients $(57.37 \%)$ possessed b3a2 fragment of $440 \mathrm{bp}, 22$ patients (36.06\%) had b2a2 of $370 \mathrm{bp}$ and 4 patients $(6.55 \%)$ had b3a3 fragment of $270 \mathrm{bp}$ (Figure 4$)$.

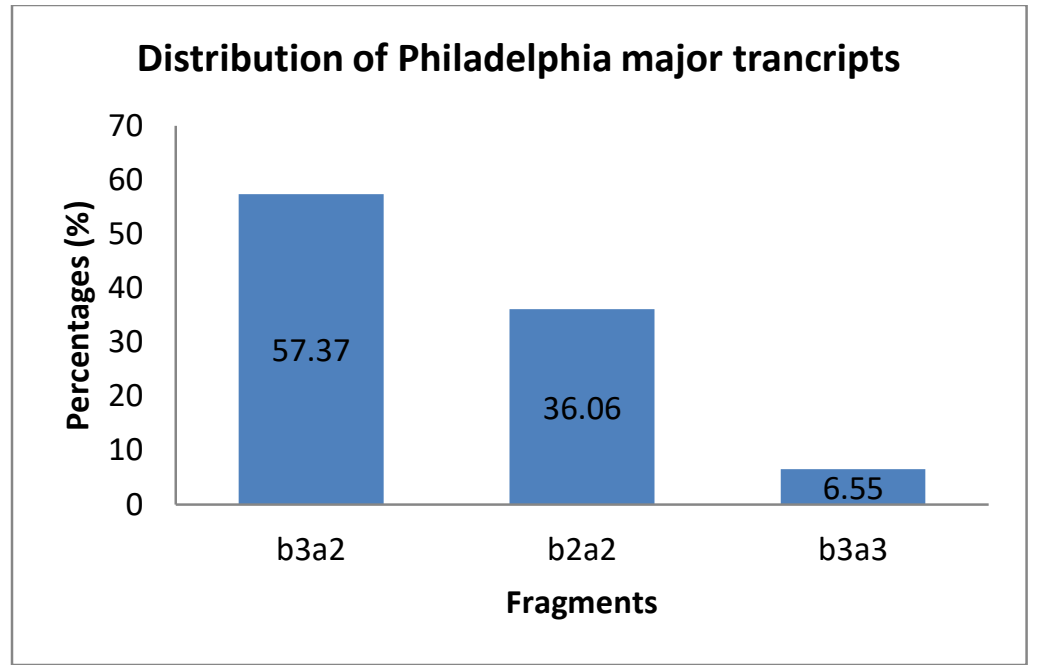

Figure 4: Percentage distribution of three Philadelphia major transcripts.

To validate conventional PCR analysis in the detection of BCR/ABL fusion transcripts, side-by-side comparison analysis with real-time PCR (Q-RT-PCR) was performed to determine the reliability of conventional PCR. It provided not only detection of the fusion gene but also quantification of the accumulated target PCR products. 


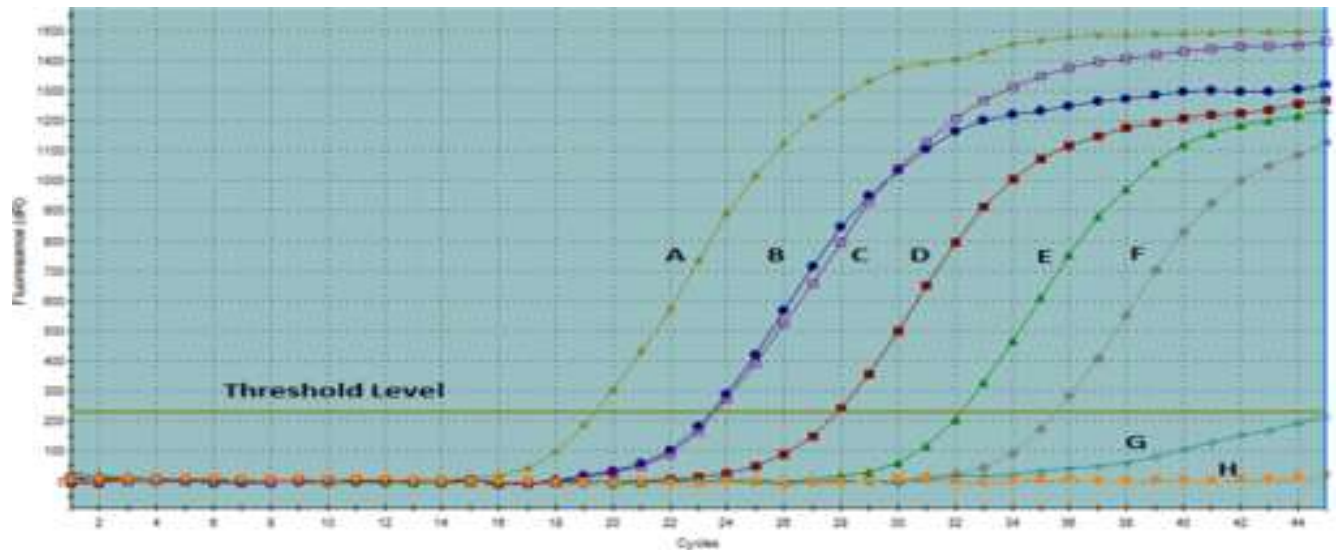

Figure 5: Real-time RT-PCR amplification plots of the BCR/ABL fusion transcripts. The BCR/ABL amplification plot of Ph-positive CML sample (labeled A, B) and a Ph-negative sample (labeled G) is shown. Standard curves (Labeled C, D, E, F) are also shown. Straight line parallel to $X$ axis denotes the threshold level above which indicates BCR-ABL positive.

Of these 87 samples, 63 samples were BCR-ABL positive and 24 samples were BCR-ABL negative as determined by real-time RT-PCR. On the other hand 61 samples were found to be BCR- ABL positive and 26 samples were BCR- ABL negative as determined by conventional PCR and ten negative controls gave no band.

From both of these analyses it was found that 77 samples had the same result. There were ten discrepancies between the conventional RT-PCR and Q-RT-PCR assays. Four samples which were positive in conventional PCR gave negative result in Q-PCR and other six samples which were positive in Q-PCR gave the negative result in conventional PCR. The 4 samples which were undetected in Real time PCR possessed b3a3 fragment.

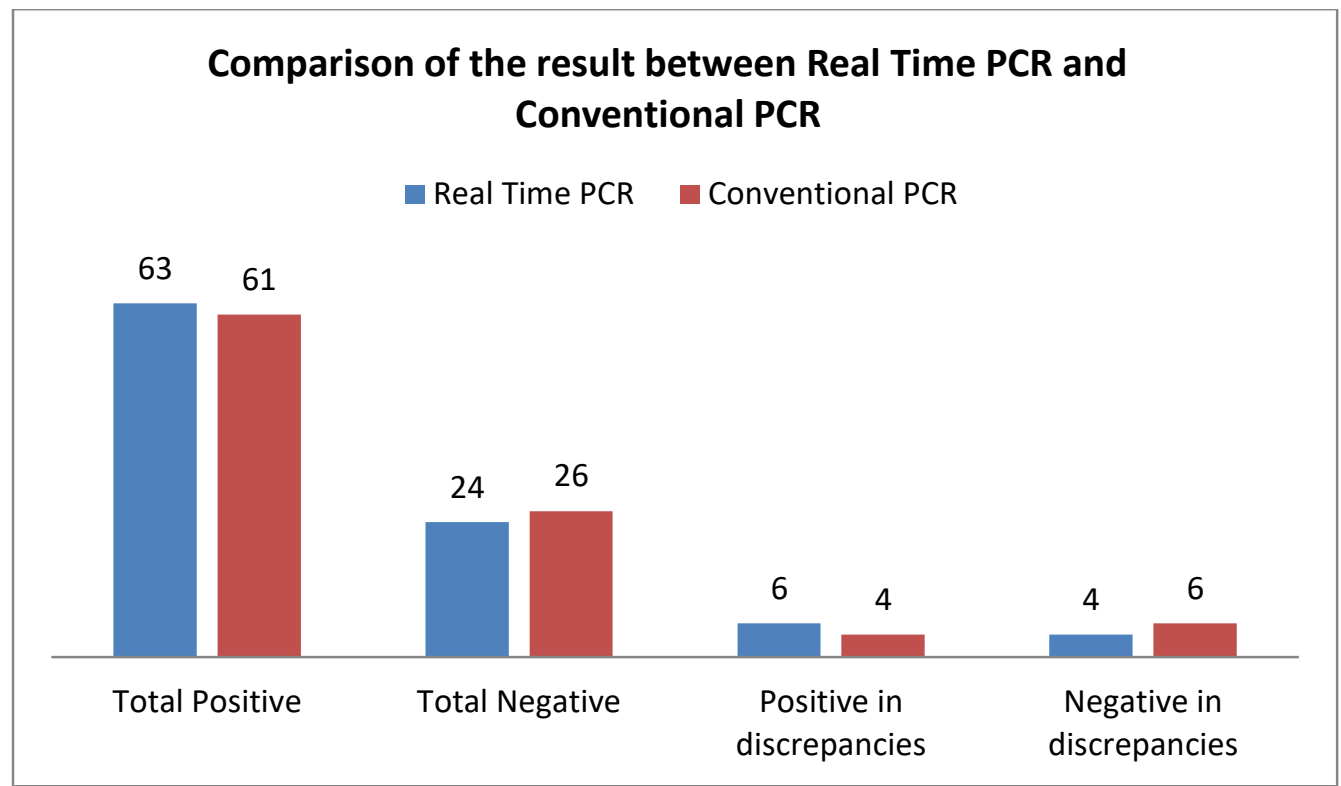

Figure 6: Parallel analysis of Real-time PCR ( $\square$ ) and conventional PCR ( $\square$ ). Numbers of patients are presented in the $\mathrm{Y}$ axis. 
Efficiency of RNA extraction was measured by using the RNA samples in agarose gel electrophoresis followed by ethidium bromide staining. After electrophoresis process, RNA concentration was measured by UV spectrophotometry. Samples with intact $28 \mathrm{~S}$ and 18S RNAs were considered adequate and were subjected to reverse transcription.

\section{Discussion}

The main purpose of the study was to establish a reliable, cost effective and easy method for the diagnosis of CML patients and characterization of the BCR-ABL translocation and produce a linkage with demographic characteristics and susceptibility to this disease.

\section{Demographic Characteristics}

In this study 62 patients were male and 25 patients were female. So the male to female ratio was 2.48:1.0. CML incidence is often found to be strongly related to gender which strongly correlates with this study. In another previous study in Bangladesh it was found that males $(67 \%)$ were affected more frequently than females $(33 \%)$; the male to female ratio was 2.1:1.0 (Mottalib et al. 2014).

Furthermore, this ratio is slightly higher than India where male: female ratio was 1.9:1.0 (Chavan et al. 2006) and Pakistan where male: female ratio was 1.7:1.0 (Syed et al. 2006). This result is similar to the result previously studied in UK and India (Chavan et al. 2006). Though the biological mechanism of this disease cannot be disregarded, the diagnostic situation in Bangladesh is further compounded; this may be a source of bias leading to an underrepresentation of the true disease burden in women.

On the other hand in case of age group the studied data was not similar with the CML patients demographic data studied in France and the USA. Here the patients whose ages were between 21-30 years were mostly susceptible to CML. CML patients mean age in France was 55 years (Tardieu et al. 2005) and in the USA it was 66 years (Aziz et al. 2007). This means the young generations of Bangladesh are now prone to develop CML. However, the main reason for the earlier occurrence of CML in our population may be because of food adulteration, exposure to carcinogenic chemicals, overuse of pesticides, smoking, exposure to radiation consumption etc. These preceding contributing factors are lower or absent in Europe and North America.

\section{Cost Effectiveness}

BCR-ABL diagnosis costs a lot with commercially imported kit. This translocation test costs seven thousand taka per patient in BSMMU. This study developed an in-house protocol which will cost maximum one thousand taka for the qualitative detection of BCRABL gene.

\section{Characterization of Junction}

Characterization of the junction is done depending on the size of the PCR products. For example, the result from a PCR performed on a transcript coding for $\mathrm{p} 210 \mathrm{BCR}-\mathrm{ABL}$ will be different depending on whether the junction is b2a2, b3a3 or b3a2. In this study, 87 patients were used for BCR-ABL characterization but of them, 61 samples were found to have Philadelphia major translocation. Of all those positive samples, $57.37 \%$ patients possessed b3a2 fragment, $36.06 \%$ patients had b2a2 and $6.55 \%$ patients had b3a3 fragment. The characterization of the BCR-ABL major transcript can't be performed by real-time PCR because the available commercial Real-time PCR kit can't detect these three fragments. 


\section{Comparison between Real time PCR and Conventional PCR}

A high concordance rate of $77 / 87$ (88.5\%) was observed between this two techniques indicating that the sensitivity and specificity of both assays were nearly equivalent. Ten discrepancies were found in the study of which four samples were positive in conventional PCR but resulted negative in Q-PCR and other six samples were positive in Q-PCR but gave negative result in conventional PCR. Further analysis of the four samples positive in conventional PCR gave evidence that these four samples were from fragment b3a3. This result concludes that commercial real-time PCR can't identify b3a3 fragment. On the other hand the six samples which were undetected in conventional PCR had BCR-ABL/ABL ratio less than $1 \%$ that means they were follow up patients and taking treatments of the cancer. So their ratios were less and might be undetected in conventional PCR. There could be other reasons which resulted in no detection in the conventional PCR. The cause of discrepancy may be due to the loss of the mRNA during RNA extraction by accidental RNase contamination, damage of the RNA by successive freeze-thaw events or less homogenization of cells or tissues. Some of the CML patients had BCR-ABL/ ABL Ratio less than $0.1 \%$ indicating major molecular remission (MMR) (Hughes et al. 2006) and ratio $<0.01 \%$ indicating complete molecular remission (CMR). Of the 6 samples (positive only in Q-PCR) 2 samples had major molecular remission due to the treatment efficiency. But most of the patients were in greater than 10 percent BCR-ABL/ABL ratio which means they were either newly diagnosed patients or the treatment procedure of the patients had less effect to reduce the transcript.

\section{Primer}

In the study primer was chosen from previous similar studies (Chasseriau et al., 2004) which gave a reliable result. Only one primer which was ABL specific and BCR specific three different primers were used for identifying three types of transcripts (major, minor and micro).

From the above comparison, it can be inferred that in case of normal diagnosis and MRD monitoring real-time PCR is the best option. But if we want to characterize and know all the fragments of BCR-ABL major, conventional PCR is the best alternative. It is also cost effective in case of diagnosis of ALL. We can't perform quantification in conventional PCR and for this purpose Q-PCR is reliable and can be used to detect the minimal residual disease, monitor the treatment outcome, and predict blastic crisis in CML patients. But in the case of ALL patients no quantification is needed because their treatment procedure is different. So performing both conventional PCR and Q-PCR can give $100 \%$ valid result without any false positive or false negative. In this way, even a single patient would never go undetected.

We hadn't found any minor and micro breakpoints of the transcript. Here the main problem is minor and micro breakpoints are rare in the Philadelphia chromosome and only major breakpoints are prevalent. The limitation of the study is that we even don't know about the validity of the primer sets for minor and micro breakpoint. Patients were included in the study from only a single hospital, which may not represent the actual clinical scenario in Bangladesh.

\section{CONCLUSION}

This study establishes that performing both Q-PCR and conventional PCR can detect each and every positive case of CML as well as give no false positive or false negative result. This study can be considered as the very first step in understanding the patterns and distribution of CML in Bangladesh. Further investigations are necessary to understand the potential risk factors and genetics of hematological malignancies in this country. 


\section{REFERENCES}

Anand MS, Varma N, Varma S , Rana KS, Malhotra P. Cytogenetic \& molecular analyses in adult chronic myelogenous leukaemia patients in north India. Indian J Med Res. 2012; 135:42-48.

Aziz Z, Iqbal J, Akram M, Saeed S. Treatment of chronic myeloid leukemia in the imatinib era. Cancer 2007 Mar 15;109(6):1138-45.

Chasseriau J, Rivet J, Bilan F, Chomel J C, Guilhot F, Bourmeyster N, Kitzis A, Characterization of the Different BCR-ABL Transcripts with a Single Multiplex RT-PCR. J Mol Diagn. 2004; 6 (4): 343347.

Chavan D, Ahmad F, Iyer P, Dalvi R, Kulkarni A, Mandava S, Das BR. Cytogenetic investigation in chronic myeloid leukemia: study from an Indian population. Asian Pac J Cancer Prev. 2006; 7(3):423.

Ding B, Zhou L, Jiang X, Li X, Zhong Q, Wang Z, Yi Z, Zheng Z, Yin C, Cao R, Liao L, Meng F. The relationship between clinical feature, complex immunophenotype, chromosome karyotype, and outcome of patients with acute myeloid leukemia in China. Dis Markers. 2015; 2015:382186. doi: 10.1155/2015/382186. Epub 2015 Apr 7.

Hermans A, Heisterkamp N, Von Lindern M, Van Baal S, Meijer D, Van der Plas D, Wiedemann LM, Groffen J, Bootsma D, Grosveld G. Unique fusion of bcr and c-abl genes in Philadelphia chromosome positive acute lymphoblastic leukemia. Cell 1987; 51:33-40.

Hochhaus A, Reiter A, Skladny H, Melo JV, Sick C, Berger U, Guo JQ, Arlinghaus RB, Hehlmann R, Goldman JM, Cross NCP. A novel BCR-ABL fusion gene (e6a2) in a patient with Philadelphia chromosome negative chronic myelogenous leukemia. Blood 1996; 88: 2236-2240.

Hooberman AL, Westbrook CA. Molecular methods to detect the Philadelphia chromosome. Clin Lab Med. 1990;10(4):839-55.

Hughes T. ABL kinase inhibitor therapy for CML: baseline assessments and response monitoring. Hematology Am Soc Hematol Educ Program. 2006:211-8.

Jobanputra V, Sivakumaran TA, Kucheria K. Assessment of Philadelphia Chromosome status in Chronic Myelogenous Leukemia (CML) Patients Using Cytogenetic and Molecular Cytogenetic Methods. J Anat. Soc. India. 1999; 48(2): 90-98.

Madashira M, Kotwal J, Kapoor R. Acute Myeloid Leukemia with BCR/ABL Fusion Chimera. Indian J Hematol Blood Transfus. 2014; 30 (Suppl 1): 280-282.

Melo J V, Hughes T P, Apperley J F, Chronic Myeloid Leukemia. Education Book 2003; 1: 132-152.

Mottalib MA, Sultana TA, Khalil MI, Gan SH, Islam MS, Choudhury S, Hossain MA. Phase distribution of chronic myeloid leukemia in Bangladesh. BMC Research Notes 2014; 7:142.

Neumann F, Herold C, Hildebrandt B, Kobbe G, Aivado M, Rong A, Free M, Rossig R, Fenk R, Schneider P, Gattermann N, Royer-Pokora B, Haas R, Kronenwett R: Quantitative real-time reverse-transcription polymerase chain reaction for diagnosis of BCR-ABL-positive leukemias and molecular monitoring following allogeneic stem cell transplantation. Eur J Haematol 2003; 70:1-10.

Ohsaka A, Hoshino S, Kobayashi M, Kudo H and Kawaguchi R. Blast crisis of Philadelphia chromosome-positive chronic myeloid leukaemia carrying micro-bcr breakpoint (e19a2 and e191a) Genomics Research Institute, SRL, Tokyo, Japan January 2002.

Pane F, Frigeri, F., Sindona, M., Luciano, L., Ferrara, F., Cimino, R., Meloni, G., Saglio, G., Salvatore, F. \& Rotoli, B. (1996) Neutrophilic-chronic myeloid leukemia: a distinct disease with a specific molecular marker (BCR/ABLwith C3/A2 junction). Blood 1996; 88:2410 -2414.

Rowley JD. A new consistent chromosomal abnormality in chromc myelogenous leukaemia identified by quinacrine fluorescence and Giemsa staining. Nature 1973; 243:290-3.

Sawyers CL. Chronic Myeloid leukemia. N Engl J Med. 1999; 340 (17):1330-40. 
Suh SP, Kee SJ, Lim WH, Song JW, Lee SK, Kim JP, Shin JH, Ryang DW. Multiplex in-cell reverse transcription-polymerase chain reaction for the simultaneous detection of p210 and p190 BCRABL mRNAs in chronic myeloid leukemia and Philadelphia-positive acute lymphoblastic leukemia cell lines. Clin Chem Lab Med 2000; 38:939-944.

Syed N, Usman M, Khaliq G, Adil S, Khurshid M. Clinico-pathologic features of chronic myeloid leukemia and risk stratification according to Sokal score. J Coll Physicians Surg Pak 2006. 16(5):336-9.

Tahira B, Asif M, Khan S, Hussain A, Shahwani MN, Malik A, Inayatullah S, Iqbal Z, Rasool M. Detection of BCR/ABL Fusion Gene by Hematological and Cytological Analysis in Chronic Myloid Leukemia Patients in Quetta, Pakistan. Asian Pac J Cancer Prev. 2015; 16(9):3793-7.

Tardieu S, Brun-Strang C, Berthaud P, Michallet M, Guilhot F, Rousselot P. Management of chronic myeloid leukemia in France: a multi-centered cross-sectional study on 538 patients. Pharmacoepidemiol Drug Saf. 2005; 14(8):545-53.

Westbrook CA, Hooberman AL, Spino C, Dodge RK, Larson RA, Davey F, Wurster-Hill DH, Sobol RE, Schiffer C, Bloomfield CD: Clinical significance of the BCR-ABL fusion gene in adult acute lymphoblastic leukemia: a Cancer and Leukemia Group B Study (8762).Blood 1992, 80:29832990.

Yaghmaie M, Ghaffari SH, Ghavamzadeh A, Alimoghaddam K, Jahani M, Mousavi SA, Irvani M, Bahar B, Bibordi I. Frequency of BCR-ABL fusion transcripts in Iranian patients with chronic myeloid leukemia. Arch Iran Med. 2008;11(3):247-51. doi: 08113/AIM.003

Zhao R C, Tarone G, Verfaillie C M. Presence of the adhesion inhibitory B1B integrin isoform on CML but not normal progenitors is at least in part responsible for the decreased CML progenitor adhesion. Blood 1997; 90 (Suppl.1):393a. 